\title{
Education, inequality and use of digital collaborative platforms: The European case
}

\author{
Jesús M. Artero
}

Cristina Borra

ORCID https://orcid.org/0000-0003-2277-8342

Rosario Gómez-Alvarez

\section{Universidad de Sevilla, Spain}

Corresponding author: Cristina Borra, Facultad de Ciencias Económicas

y Empresariales, Universidad de Sevilla, Ramon y Cajal 1, Sevilla

41018, Spain. Email: cborra@us.es

\section{Abstract}

This study examines the causal relationship between education and the use of digital collaborative platforms (DCPs) as a first step in exploring the potential impact of the new digital labour markets on inequality. From the viewpoint of transaction costs theory, the less educated could benefit significantly from the digital collaborative economy due to the reduction in information costs made possible by this new form of exchange. Conversely, a positive relationship between educational level and platform use may be expected following neoclassical and institutionalist economic theories. Using microdata from the 2016 Eurobarometer survey, together with an instrumental variables (IV) strategy and conventional ordinary least squares (OLS) models, hypothesis testing reveals that education has a clear positive effect on DCP use. As a result, the less educated are less likely to access the job opportunities offered by digital labour markets. Understanding the relationship 
between education and access to DCPs and impacts on socio-economic inequality is crucial for designing future public policies that promote social justice and wellbeing in a disrupted landscape.

\section{JEL codes: I24, J47, O34}

\section{Keywords:}

Inequality, digital collaborative platforms, education, non standard employment, Fourth Industrial Revolution, 4IR

\section{Introduction}

Digital Collaborative Platforms (DCPs) are one of the most disruptive innovations taking place in the Fourth Industrial Revolution (De Ruyter et al., 2019; De Stefano, 2015). Collaboration via platforms is continually gaining ground on conventional business models, and the profits obtained via these platforms are expected to increase from 15 billion dollars in 2015 to 335 billion in 2025 (PwC, 2015). This phenomenon has given rise to numerous debates on the concept of DCPs itself and its possible economic, political, social and cultural consequences (Belk, 2010; 2017; European Commission, 2016; Flanagan, 2017; Arcidiacono et al., 2018; Pesole et al., 2018).

Awareness of the impact of educational inequality as a possible barrier to accessing DCPs for both suppliers and users is a prominent feature in these debates. Therefore, an analysis of the relationship between education and access to these platforms can make an important contribution to the current discussion of the possible effects of the new digital labour markets (Acquier et al., 2017). As Martin (2016) argues, the sharing economy is perceived in contrasting and contradictory ways, whether as a pathway to sustainability or as a nightmarish form of neoliberal capitalism. Success stories such as Airbnb and Uber 
have led to the media, ICT industries and the general public having a common view of the sharing economy as a disruptive agent that modifies established socio-economic structures. Hence, from a political perspective, it is important to understand the relationship between educational inequality and access to DCPs and to ascertain the extent to which educational differences act as a barrier to the economic and social benefits these platforms can provide. Similarly, it is important to know how the design of educational and regulatory policies on working and fiscal conditions and privacy may affect the evolution of the digital economy. A greater understanding of the relationship between educational level and use of collaborative platforms is crucial to predict the effects of participation in digital labour markets on inequality and to determine what type of regulatory policies may be required.

From a theoretical perspective, the new opportunities created by DCPs could either increase or reduce social inequalities. DCPs drastically reduce transaction costs, especially those related to searching for information and negotiating contracts (Williamson, 1981). Nowadays, millions of transactions take place that did not in the past, opening up new possibilities for society as a whole and facilitating the reallocation of wealth towards small producers and consumers (Sundararajan, 2016). Nonetheless, the strong link between ICTs, platforms and new business models also entails greater demands for educational competencies (Schor and Attwood-Charles, 2017; Cansoy and Schor, 2016; Smith, 2016; Goldin and Katz, 2008). Thus, inequality in participation in DCPs could arise from lack of adequate knowledge. Furthermore, in the context of asymmetric information, education credentials may also signal those better equipped to navigate the changed labour market (Thurow, 1975; Sobel, 1982). If use of DCPs requires high qualifications, better-qualified individuals will gradually take over employment opportunities, traditionally contracted offline and undertaken by persons with few qualifications, as an alternative or supplementary source of income, thereby creating a crowding-out effect that will also 
increase inequality (Frenken and Schor, 2017; Andreotti et al., 2017; Minter, 2017; Stanford, 2017). The question is whether educational barriers are large enough to offset the potential equalising impact of reduced transaction costs.

The limited empirical evidence available on education and use of digital platforms is confronted with two fundamental problems. First, lack of data is a widespread shortcoming, either because platforms do not provide data access or because the official statistics do not address the necessary issues (Abraham et al., 2018). Thus many studies are limited to simply documenting the educational group that individual participants come from, without estimating the probability of participation within each educational group. Moreover, most studies are qualitative analyses (see, e.g. Schor, 2017), and the few quantitative analyses use data from a specific platform (e.g. Cansoy and Schor (2016) and Quattrone et al. (2016) from Airbnb, and Fraiberger and Sundararajan (2015) from Getaround) and obtain contradictory results.

The second shortcoming comes from the fact that, to the best of our knowledge, no study aims at obtaining an unbiased estimate of the impact of educational level on the use of collaborative platforms. Individuals who invest in a university education, for example, differ from those who do not in many unobserved aspects, such as subjective individual discount rates or cognitive abilities, which prevent a mere comparison of platform participation rates of both groups from being informative regarding the causal effect of education (Lemieux, 2006). Moreover, the relationship between educational level and platform use may present problems of reverse causality. The growing weight and relevance of the new digital business model in the economy may motivate the spread of new curricula directly related to the study of digital platforms so that use of platforms and educational level mutually affect each other (Newlands et al., 2018). 
We use microdata from a 2016 Eurobarometer survey on the use of collaborative platforms, corresponding to the 28 member states of the European Union, to estimate the causal relationship between educational level and participation in DCPs. We use the number of universities existing in the respondent's region of residence when they were aged 16 according to the European Tertiary Education Register (ETER, 2018) as an instrumental variable of educational level to estimate the unbiased effect of education on the probability of participation (Card 1995, 1999; Currie and Moretti, 2003; Hryshko et al., 2012). The justification of the instrument is based on the fact that the availability of universities plays a central role in the decision to enrol in higher education (Card 1995), while it does not seem to have a direct influence on the use of collaborative platforms. Our model incorporates region fixed effects to consider the permanent differences between regions, including different levels of income and wealth across regions, and cohort fixed effects to consider the common trends in platform use across individuals of the same age. Thus, our estimates are identified by differential changes in the availability of educational services between regions and cohorts. It should be noted that the regional distribution of higher education institutions is linked to regional income and wealth and consequently, the regional distribution of participation in higher education and access to digital platforms may reflect existing inequalities. However, our estimates are based on changes in college availability across regions over time and assume away permanent correlations of wealth and availability of higher education institutions within regions.

The results of both the instrumental variables (IV) approach and the ordinary least squares (OLS) model suggest that education increases the probability of using digital platforms. Specifically, one more year of education increases the likelihood of using digital platforms by 5.03 percentage points. Furthermore, having university education or higher entails an increase of 75 percentage points in the probability of platform use, which 
suggests that the profile of the typical user is a highly qualified individual. The heterogeneity analysis by area of residence shows that our results are mainly driven by countries in the EU-15, given that the instrumental approach is not valid for countries in the Eastern Bloc. The gender-based results do not show appreciable differences between men and women.

Our results are highly relevant in the current context of the Fourth Industrial Revolution, greatly accelerated by the recent COVID-19 Crisis. When innovations extend to all economic spheres (Schwab, 2016), companies need highly adaptive, most likely educated, workers (Krueger and Kumar, 2004; Van Dijk, 2005).

This study examines the causal impact of education on DCP use, but due to limitations in the data it does not address benefits potentially generated by digital platforms, such as improved convenience, cost savings, time savings, and increased income. We find that education increases access, but we cannot guarantee that access generates tangible benefits, given that increasing access does not necessarily mean increasing benefits.

This study makes significant contributions to the growing literature on DCPs. To the best of our knowledge, our study is the first to analyse the causal effect of educational level on the use of digital collaborative platforms. Contrary to quantitative empirical studies, such as those of Cansoy and Schor (2016) and Quattrone et al. (2016), we use quasiexperimental techniques to control for the possible presence of endogeneity and unobserved heterogeneity in estimating the causal effect of educational level on the use of digital platforms. Furthermore, in contrast to most studies which analyse the educational profile of participants by focusing on specific platforms, we use a database that considers digital platforms in general and includes information on both participants and nonparticipants in DCPs. As a result, we are able to quantify the effect of educational level on the probability of participating in any digital platform in Europe. 


\section{Theoretical considerations: Collaborative economy, digital platforms and educational inequality}

Digital platforms are technological building blocks acting as a foundation upon which other firms develop complementary products (Gawer, 2009). Examples range from Microsoft Windows to Google. Digital platforms are usually subject to scale and scope economies in the sense that large fixed costs contrast with close to zero marginal costs and the value of the service increases with the number of users (OECD [Organisation for Economic Cooperation and Development], 2017). DCPs refer to digital platforms that function as intermediaries between providers and users (or workers and end-users) facilitating exchange by enabling information sharing and secure payment systems (Stewart and Stanford, 2017). According to the European Commission (2016), DCPs involve three categories of actors: i) service providers who share assets, resources, time and/or skills. These can be private individuals offering services on an occasional basis ('peers') or service providers acting in their professional capacity ('professional service providers'). ii) Users of these services iii) Intermediaries that connect providers with users via an online platform and facilitate transactions between them ('collaborative platforms'). As a consequence, not every digital platform is a DCP. DCPs' main objective is to act as brokers between users and providers, facilitating exchange.

To what extent does education constitute an entry barrier to DCPs? One can distinguish two sets of theoretical expectations for the relationship between educational inequality and use of DCPs. The first hypothesis stems from the reduction in transaction costs enabled by the collaborative economy (Williamson, 1981; Sundararajan, 2016). ${ }^{1}$ Technological transformations enable handling and transport of information, that is, digital information, at a much lower cost. The exponential growth in hardware capacity has facilitated the proliferation of devices among the population that enable permanent connectivity and the 
continuous emergence of new applications. These technological transformations have made it possible to create systems of reputation and trust among strangers. In summary, the collaborative economy may open new possibilities to all social classes (Andersson et al., 2013). As such, it represents an innovation that is capable of reallocating wealth across the 'value chain' towards small producers and consumers. This hypothesis has been supported by empirical studies that provide positive results for low socio-economic profiles via the use of platforms (see Table B.1). Fraiberger and Sundararajan (2015) simulate a dynamic model of a P2P (peer to peer) market for vehicles with data from the Getaround platform, which predicts an exponential profit for the group below the median income (lower educational profile). Quattrone et al. (2016) use data from Airbnb listings and the London census, showing the growing presence of accommodation in poorer districts and among owners of low educational level.

The second hypothesis assumes that a minimum educational level is required to use ICTs. Therefore, use of DCPs to access goods and services and education level are positively related. Torero and von Braun (2006) show that access to ICTs depends on income, education and resources and that the so-called digital divide is part of a much broader development divide. They argue that socio-economic development contributes to a greater use of ICTs rather than the reverse. Regarding service suppliers, both neoclassical and institutional economists theorise that technological change will favour the labour market outcomes of the highly educated. For example, developments in the neoclassical human capital theory emphasise the higher-level labour-market skills required by technological change (Goldin and Katz, 2008) ${ }^{2}$. In addition, institutionalists' job competition theories argue that educational qualifications signal more able individuals (Thurow, 1975). ${ }^{3}$ In this scenario, the higher educated may have an advantage in securing employment in low-skilled jobs, crowding out the employment opportunities for those with 
lower levels of education (Gautier et al., 2002; Di Stasio et al., 2015). This trait is also likely to be reproduced in the collaborative economy, especially in the so-called cloud work or crowd work of online labour markets (OLMs), which are potentially global, and not so much in the gig work or on-demand work of mobile labour markets (MLMs), which are geographically localised (Codagnone et al., 2016). ${ }^{4}$

From an empirical perspective, many descriptive studies support the positive relationship between education and the use of DCPs (see Appendix Table A.1). For the United States, Smith (2016) reports that $89 \%$ of college graduates have used DCPs, and $39 \%$ have used four or more of these services compared with just $8 \%$ of those with a high school degree or less. Through 80 semi-structured interviews with active users of DCPs, Schor et al. (2016) qualitative analysis highlights the high educational profile of users of four specific platforms: Wintrepreneur, CraftWorks, Food Swap, and Time Bank.

Similarly, DCP providers are also specially selected among the highly educated. Schor (2017) interviewed 43 suppliers of three platforms in the United States, Airbnb, RelayRides and TaskRabbit, between 2013 and 2015 and provides a profile of a platform participant who is highly educated and engaged in other high-skilled jobs. These people displace the workers of a low educational profile who have traditionally done much of the manual labour characterised in conventional business models, but which is progressively more concentrated on collaborative platforms. Ravenelle (2017) interviewed 78 suppliers of Airbnb, TaskRabbit, Kitchensurfing and Uber in New York in 2015, and found that more than $61 \%$ of those interviewed had higher education qualifications. Thebault-Spieker et al. (2015) use a fixed-effects logistic estimation model and a subsequent qualitative analysis of 40 suppliers of TaskRabbit interviewed in the Chicago area. The results revealed that those living in neighbourhoods of low socio-economic profile needed to pay an extra charge to contract service providers. Cansoy and Schor (2016) use a database with 125,000 listings of 
accommodations in Airbnb from 104 metropolitan areas in the United States for 2015 and 2016 together with country census data and find that education is the most important determinant explaining the number of listings, nightly prices, and user ratings.

\section{Data and empirical method}

\section{Data}

To test our hypotheses, we use data from the 2016 Eurobarometer 'The use of collaborative platforms'. This telephone survey carried out at the request of the European Commission was intended to gain greater understanding of the role of collaborative platforms in the growth, employment and benefits of consumers in Europe using data on the perception, attitudes and practices of individuals in the platforms. It enables the construction of sociodemographic profiles of the participants (nonparticipants) in the platforms at European level. The sample population is 14,050 individuals aged 15 or over, representative of the 28 member states of the EU.

Our dependent variable is the probability of using collaborative platforms, which is measured by answers to the following question: 'A collaborative platform is an Internetbased tool that enables transactions between people providing and using a service. They can be used for a wide range of services, from renting accommodation and car sharing to small household jobs. Which of the following matches your experience regarding this type of platform?' The possible responses are: 1) You have never heard of these platforms. 2) You have heard of these platforms, but you have never visited them. 3) You use the services of these platforms occasionally (once every few months). 4) You use the services of these platforms regularly (at least every month). The indicator of participation in digital platforms was constructed from the responses; 'participants' were those who indicated they use the platforms occasionally or regularly. 
Our key independent variable is educational level. Our main measure of education was the number of years of schooling, obtained by subtracting the age of access to primary education for each country of the EU-28 (European Commission, 2018) from the age at which the respondent finished studying. We also offer a supplemental analysis using an indicator for being a college graduate as an alternative measure of education. Additionally, we include indicators for females and living in rural areas as controls, together with cohort and region of residence fixed effects. Table B.2 in the Appendix summarises variable construction and Table B.3 provides descriptive statistics for the dependent, independent and control variables.

Respondents participating in platforms accounted for only $17.8 \%$ of all those surveyed. This was expected, given that the average age was 54 years and younger generations are usually more technology oriented. The average number of years of schooling was about 14 and about $40 \%$ of respondents were college graduates. Most lived in urban areas, with $31.3 \%$ living in rural areas.

\section{Figure 1 about here}

Together with the Eurobarometer data, we use data from the European Tertiary Education Register (ETER, 2018), which compiles information from tertiary education institutions for the EU-28, including 10,770 observations on universities, as well as their location and year of foundation. We use these data to construct our instrument: the number of universities in each NUTS2 (Nomenclature of Territorial Units for Statistics 2) region each year from 1934 to 2016 (see trends in Figure 1). When assigning the instruments to individuals in the Eurobarometer, we assign values corresponding to the year when the individual was 16 , to be relevant for educational choices towards the end of high school. The Eurobarometer identifies the region of residence at the time of undertaking the survey, not the region of residence when the individual was 16 . We assume that both regions 
coincide. European Commission estimates indicate that the degree of regional mobility in the European Union does not exceed 1\%, and thus, this assumption should not be a problem in practice (Verwiebe et al., 2014; European Commission, 2006).

\section{Empirical strategy}

Our model assumes that the probability of using DCPs depends on the educational level of the individual as well as a set of observable (Xi) and unobservable factors. Our basic equation for estimation is

$$
U_{S E_{i c r}}=\propto+\beta E D U C A T I O N_{i}+\gamma X_{i}+\mu_{c}+\rho_{r}+\varepsilon_{i c r}
$$

where USE is an indicator taking value one if the individual $i$ from cohort $c$ and region $r$ reports using DCPs. EDUCATION is years of schooling (or the college graduate indicator in the supplemental analysis). $X i$ is a vector of controls including gender and rural residence. Cohort fixed effects $\mu_{c}$ account for differences in educational attainment and ICT skills common to all individuals born in the same year. Region fixed effects $\rho_{r}$ account for systematic differences in education and ICT skills across regions. $\varepsilon_{i c r}$ are robust standard errors.

For the IV approach, we assume that education is determined by the same factors as platform use and by an instrument reflecting college availability. In interpreting the results, we assumed that the effects of education on the probability of platform use depend on unobservable factors and that the IV estimates will represent local average treatment effects (LATE). ${ }^{5}$ In particular, the first-stage equation is

$$
\text { EDUCATION }_{i c r}=\propto_{1}+\beta_{1} Z_{c r}+\gamma_{1} X_{i}+\mu_{c}+\rho_{r}+u_{i c r}
$$

where $\mathrm{Z}$ is the instrumental variable offering the number of universities in region $r$ the year the individual was 16 years old. ${ }^{6}$ 


\section{Results}

\section{Main findings}

The OLS results in Column 1 of Table 1 show a significant correlation between participation in digital platforms and years of schooling. In line with the literature and our hypotheses which identify a highly qualified profile in the platforms (Schor, 2017; Cansoy and Schor, 2016; Smith, 2016; Quattrone et al., 2016; Edelman et al., 2017; Ravenelle, 2017), one more year of study increases the probability of participation by 0.59 percentage points or $3.3 \%$.

Column 2 of Table 1 reports the results for the main IV model that uses regional availability of university institutions to instrument for years of schooling. The results of the last two rows confirm that the number of universities in the region when the individual is aged 16 is a good instrument; the F-stat from the first-stage regression is equal to 23.30, larger than the recommended size of 10 (Stock and Yogo, 2005). Moreover, the positive and significant coefficient of the instrument confirms that the opening of universities favoured the increase in the years of study of the individuals: one additional university in the region of residence of the individual when they were 16 increases years of study by 0.02 years (approximately 1 week).

The estimates from the second-stage regression in Column 2 of Table 2 are larger than the OLS estimates in Column 1 of Table 2. In particular, the estimated impact of one more year of schooling increases almost tenfold, from 0.6 percentage points in Column 1 to 5.0 percentage points in Column 2. Table B.5 in the Appendix shows that these findings are robust to using an alternative measure of education, such as being a college graduate. These findings are in line with the results of Cansoy and Schor (2016), where the number of Airbnb listings increases fivefold for each marginal increase in the standard deviation in education, or the results of Quattrone et al. (2016), who find that the probability of listing 
rooms on Airbnb is 10 percentage points for individuals with higher studies. Similarly, Schor (2017), documents that $70 \%$ of participants in TaskRabbit have a university degree, $20 \%$ have a master's degree, and 5\% have a doctorate, while Smith (2016) reports that 29\% of college graduates have used ride-hailing services compared with $6 \%$ among those who have not attended college, and $25 \%$ have used home-sharing platforms compared with $4 \%$ among the non-college population.

[Table 1 here]

Notice that larger IV estimates than the corresponding OLS estimates have been frequently reported in the literature (Card, 1995; 1999; Currie and Moretti, 2003). There have been two main explanations: first, the presence of measurement errors that skew the OLS results towards zero, and second, the fact that the IV estimates are local average treatment effects (LATE) (Imbens and Angrist, 1994). In our case, the size of the difference leads us to believe that our results are not due to a measurement error. However, as emphasised by Card (2001), it does seem appropriate to assume that the individuals affected by the policy of opening university centres are individuals with high returns to education, not only in terms of greater potential income from work but also in terms of learning about the necessary information technologies to access DCPs. This fact does not invalidate our empirical strategy but rather shows that the two methodologies measure different realities. While OLS associations are more important in terms of describing the phenomenon, the IV estimates are important with regard to educational policy. Given that the individuals affected by our treatment variable will be closer to the target population of improvements in educational provision, from a policy perspective, the impact of investments in education on participation in the digital economy will be closer to our IV estimate than our OLS estimate. 


\section{Heterogeneous impacts}

Results from Table 1 (and Table B.4 in the Online Appendix (SAGE TYPESETTER PLEASE IBSERT HYPERLINK) show that the relationship between increased education and use of DCPs is generally persistent and statistically significant. However, we should determine if a specific demographic or geographic group is driving our results. We therefore stratify the sample with respect to gender and regional variables and reestimate the model.

The results of Table 2 show that although one more year of study is associated with a lower probability of using the platforms for women (Column 1) than for men (Column 3) in the OLS specifications, when the availability of universities is used as an instrument (Columns 2 and 4), there are no significant differences in the unbiased impact of one more year of study between women and men. In both cases, one more year of study increases the probability of accessing DCPs by approximately 5 percentage points. Therefore, it can be said that education produces a similar impact on access to platforms in both men and women. This finding is also a novelty of our study, and although previous analyses have documented that digital labour is surprising evenly divided by gender (see for instance Huws et al., 2017), we have not found any evidence on participation on digital markets by gender and education level.

Table 3 distinguishes survey respondents in the EU-15 from those who reside in the countries that joined in or after 2004 (new accession countries from the Eastern Bloc). The results of the last two rows of Columns 2 and 4 show that although the number of universities is a good instrument in the EU-15 group of countries, it is not valid in the new accession countries of the Eastern Bloc. For the countries of the EU-15, one more year of study was associated with an increase in the probability of platform use of 0.6 percentage points or $3 \%$ in the OLS specification (column 1) and caused an increase in the probability of use of 3.6 percentage points or $20 \%$ in the IV specification. For new accession countries 
from the Eastern Bloc, education and platform use were also positively related in the OLS specification: one more year of study was associated with an increase in the probability of using DCPs by approximately $0.7 \mathrm{pp}$ (column 3). We cannot estimate the causal impact of one more year of study for this group, but this positive impact is consistent with the findings for the EU-15 group in Column 1. To the best of our knowledge, no previous studies have documented differences in participation in digital markets by European country group and education level.

[Table 2 here]

[Table 3 here]

\section{Discussion}

This study provides new evidence on the impact of educational inequality on access to DCPs, using data from the Eurobarometer 438, 'The use of collaborative platforms'. By exploiting changes in accessibility to university education across regions and cohorts in an IV approach, we find that years of schooling impact positively on the use of DCPs, in line with the previously reported high-skill profile of digital platform users (Schor, 2017; Cansoy and Schor, 2016; Smith, 2016; Quattrone et al., 2016; Edelman, et al., 2017; Ravenelle, 2017)For both OLS and IV estimates, we found a positive relationship between educational level and DCP use, irrespective of gender and country of origin. Our results provide suggestive evidence that education constitutes an effective barrier to access to the digital economy, which the reduction in transaction costs enabled by DCPs is insufficient to overcome. Similarly, regarding the use of the Internet, DiMaggio et al. (2004) demonstrated that equality in access is not achieved through public investment in infrastructure alone: knowledge and education are also needed.

The educational barriers to DCP use may have several implications for access inequality in the digital labour markets as it may impact both supply of and demand for 
labour. First, from the perspective of labour supply, low-educated individuals may fail to gain access to the new jobs created in the digital economy (Schor and Attwood-Charles, 2017) owing to the complexity of new technologies, which constitutes a fundamental barrier differentially disadvantaging lower-educated people (Roger, 2005). Second, the more highly educated may replace the less educated in low-skilled jobs that are now performed online (Schor, 2017). Third, DCP use can provide privileged access to information on desirable jobs and highlight the positive qualities of potential workers, thus widening the inequality gap (DiMaggio and Bonikowski, 2008). Fourth, DCPs open new job and human capital investment opportunities that may be disproportionally monopolised by the higher educated (DiMaggio et al., 2004).

With respect to labour demand, in the ever-changing environment characteristic of the Fourth Industrial Revolution, firms require more educated individuals who tend to possess more general skills and are better able to adapt to new production technologies (Krueger and Kumar, 2004; Van Dijk, 2005). Moreover, companies use education as a signal of workers' ability to adapt continuously and learn new skills and approaches within a variety of contexts.

\section{Limitations}

While this study has made a significant contribution to identifying the relationship between educational inequality and use of digital platforms, its findings should be interpreted in the light of several limitations that future research may seek to overcome. First, additional data are needed to investigate the causal pathways linking education to DCP use. Education can neither increase productive knowledge, as implied in human capital theory (Lochner, 2011), nor can it solely affect the quality of the social network available to an individual (CalvóArmengol and Jackson, 2004). In the first case, pursuing a university education would increase students' chances of successfully engaging with DCPs, depending on the curricular 
content of the specific studies in which they enrol; in the second case, their participation in the new digital forms of exchange would fundamentally depend on their ability and the technological curiosity of their classroom peers. Similarly, an implicit assumption in our analysis is that accessing DCPs benefits its users. Additional data are needed to investigate the types of benefits potentially generated by different types of users, such as consumers versus labour providers. Conducting further surveys detailing the benefits obtained by DCP participants and the curricular contents of their studies will likely tackle these issues.

A third limitation arises from the use of one-year, cross-sectional data from the European Union. While the European Union is a diverse group of countries, the generalisability of our findings may be subject to differences in university funding, entry requirements, facilities and infrastructure. These differences may limit the validity of this study beyond the European Union.

A fourth limitation may be that our instrument considers all university programmes, without making content-related distinctions. While we are able to discriminate between private and public universities, investigating the different impacts of university places on science versus social programmes may prove to be an interesting avenue for further research. Finally, we have not broached the question of inequality in digital labour markets. Whether there are differences in participation in these markets depending on educational status, whether there are similar education gaps in online and MLMs, and whether service providers use digital labour markets as a primary or supplementary source of income are all interesting issues that we would like to address in the future.

\section{Conclusions}

Notwithstanding these limitations, out study suggests that DCPs increase socio-economic inequality and underline the need to propose economic policies that reduce the gap in educational inequality, especially given the current growth in precariousness, both in 
traditional and gig-economy labour markets (Flanagan, 2017; Stanford, 2019). If highly educated individuals benefit most from the digital economy, the obvious policy solution is to ease access to university education by increasing provision of university places and through awarding scholarships and reducing public tuition fees (Agrawal et al., 2019). Moreover, our first-stage model underlines how the availability of university centres in an individual's region of residence affects the likelihood of pursuing higher education. Channelling resources towards regions with fewer university places could prove to be a compelling policy option for increasing educational attainment and reducing inequality in DCP use. Additionally, policies should identify demographic groups suffering the most from the digital divide (Wu et al., 2015; Goedhart et. al., 2019) and target specific resources towards them.

Finally, public policies must advance digital preparedness by including digital skills into educational curricula and across educational levels. It is difficult to map the competencies and skills expected in industries not yet created (Schwab, 2016). Although Van Laar et al. (2017) argue that 21st-century skills are broader than digital skills, the technical, information management and communication skills characteristic of digital literacy are considered core skills, fundamental for performing tasks that are needed in a broad range of occupations. Other skills are also important, but digital skills are a prerequisite for many $21^{\text {st }}$ century occupations.

Our study suggests that higher-educated individuals will have easier access to the new jobs that will be demanded in the Fourth Industrial Revolution, accentuating socioeconomic inequality with respect to the less educated. Undoubtedly, the COVID-19 virus pandemic is a clear example of how companies and individuals who have the characteristics and knowledge to carry out activities in the digital field have not had to suspend productive activity and have continued obtaining income, compared to other 
sectors that have had to cease operating completely. The quantitative analysis presented herein may shed light on the impact of educational inequality on platform use, facilitating the discussion on what DCPs are today and what they can become in the future.

\section{Declaration of conflicting interests}

The authors declared no potential conflicts of interest with respect to the research, authorship and/or publication of this article.

\section{Funding}

The authors received no financial support for the research, authorship and/or publication of this article.

\section{References}

Abraham K, Haltiwanger JC, Sandusky K, Spletzer JR (2018) Measuring the gig economy: current knowledge and open issues. Cambridge MA: NBER Working Paper No. 24950.

Acemoglu D (2002) Technical change, inequality, and the labor market. Journal of Economic Literature 40(1): 7-72.

Acquier A, Daudigeos T and Pinkse J (2017) Promises and paradoxes of the sharing economy: an organizing framework. Technological Forecasting and Social Change 125: 1-10.

Agrawal A, Gans J and Goldfarb A (2019) Economic policy for artificial intelligence. Innovation Policy and the Economy 19(1): 139-159.

Andersson M, Hjalmarsson and Avital M (2013) Peer-to-peer service sharing platforms: driving share and share alike on a mass-scale. Paper presented at Thirty Fourth International Conference on Information Systems. Milan. Available at: https://pdfs.semanticscholar.org/a5d1/c8142c5b5e83166745a00d59afa74b189397.pdf (accessed 4 June 2020). 
Andreotti A, Anselmi G, Eichhorn T, Hoffmann CP and Micheli M (2017) Participation in the sharing economy. SSRN Electronic Journal. Available at:

https://papers.ssrn.com/sol3/papers.cfm?abstract_id=2961745_(accessed 14 January 2020).

Arcidiacono D, Gandini A and Pais I (2018) Sharing what? The 'sharing economy' in the sociological debate. The Sociological Review 66(2): 275-288.

Belk R (2010) Sharing. The Journal of Consumer Research 36(5): 715-734.

Belk R (2017) Sharing without caring. Cambridge Journal of Regions, Economy and Society 10(2): 249-261.

Becker G (1962) Investment in human capital: a theoretical analysis. Journal of Political Economy 70(5): 9-49.

Calvó-Armengol A and Jackson MO (2004) The Effects of Social Networks on Employment and Inequality. American Economic Review 94 (3): 426-454.

Cansoy M and Schor JB (2016) Who gets to share in the 'sharing economy': understanding the patterns of participation and exchange in Airbnb. Boston College. Available at: https://www.bc.edu/content/dam/files/schools/cas_sites/sociology/pdf/SharingEconomy.pdf (accessed 4 June 2020).

Card D (1995) Using geographic variation in college proximity to estimate the return to schooling.

In Christofides LN, Grant EK and Swidinsky RR (eds) Aspects of Labor Market Behaviour: Essays in Honour of John Vanderkamp.Toronto ON: University of Toronto Press, pp. $1801-1863$.

Card D (2001) Estimating the return to schooling: progress on some persistent econometric problems. Econometrica 69(5): 1127-1160.

Coase RH (1960) The problem of social cost. Journal of Law and Economics 3: 1-44.

Codagnone C, Abadie F, Biagi F (2016) The Future of Work in the 'Sharing Economy'. Market Efficiency and Equitable Opportunities or Unfair Precarisation? European Commission. Institute for Prospective Technological Studies, JRC Science for Policy Report. EUR 27913 EN, doi:10.2791/431485. 
Currie J and Moretti E (2003) Mother's education and the intergenerational transmission of human capital: evidence from college openings. Quarterly Journal of Economics 118(4): 15531604.

De Ruyter A, Brown M, Burgess J (2019) Gig work and the fourth industrial revolution: conceptual and regulatory challenges. Journal of International Affairs 72(1): 37-50.

De Stefano V (2015) The rise of the just-in-time workforce: On-demand work, crowdwork, and labor protection in the gig-economy. Comparative Labour Law and Policy Journal 37(3): 471.

DiMaggio P, Hargittai E, Celeste C, and Shafer S (2004) From unequal access to differentiated use: a literature review and agenda for research on digital inequality. In Neckerman K (ed) Social Inequality. New York NY: Russell Sage Foundation, pp. 355-400.

DiMaggio P and Bonikowski B (2008) Make money surfing the web? the impact of internet use on the earnings of US workers. American Sociological Review 73(2): 227-250.

Di Stasio V, Bol T and Werfhorst H (2015) What makes education positional? Institutions, overeducation and the competition for jobs. Research in Social Stratification and Mobility 43: $1-11$

Edelman BG, Luca M and Svirsky D (2017) Racial discrimination in the sharing economy: evidence from a field experiment. American Economic Journal Applied Economics 9(2): 122.

European Tertiary Education Register [ETER] (2018). Brussels: European Commission. Available at: https://www.eter-project.com/\#/home on November 30, 2018 (accessed 14 January 2020).

Eurobarometer (2016) The use of collaborative platforms. Flash Eurobarometer 438 Report. Brussels: European Commission. Available at https://data.europa.eu/euodp/es/data/dataset/S2112_438_ENG (accessed 2 September 2017).

European Commission (2006) Employment in Europe Report 2006. Brussels: European Commission, Directorate-General for Employment, Social Affairs and Equal Opportunities. 
European Commission (2016) A European agenda for the collaborative economy. Available at: https://eur-lex.europa.eu/legal-content/EN/TXT/?uri=COM\%3A2016\%3A356\%3AFIN (accessed 14 January 2020).

European Commission/EACEA/Eurydice (2018) The structure of the European education systems 2018/19: Schematic Diagrams. Eurydice Facts and Figures. Luxembourg: Publications Office of the European Union.

Flanagan F (2017) Symposium on work in the 'gig' economy: Introduction. The Economic and Labour Relations Review 28(3): 378-381.

Fraiberger S and Sundararajan A (2015) Peer-to-Peer Rental Markets in the Sharing Economy. New York NY: NYU Stern School of Business Research Paper. Available at: https://www.hbs.edu/faculty/conferences/2016dids/Documents/Fraigerber_Sundararajan_March2016.pdf (accessed 4 June 2020). Frenken K and Schor J (2017) Putting the sharing economy into perspective. Environmental Innovation and Societal Transitions 23: 3-10.

Gautier PJ, van den Berg GC, van Ours J and Ridder G (2002) Worker turnover at the firm level and crowding out of lower educated workers. European Economic Review 46(3): 523-538. Gawer A (ed.) (2009) Platforms, Markets and Innovation Cheltenham, UK: Edward Elgar.

Goedhart N, Broerse J, Kattouw R, Dedding C (2019) Just having a computer doesn't make sense: The digital divide from the perspective of mothers with a low socio-economic position. New Media and Society 21(11-12): 2347-2365.

Goldin C and Katz L (2008) The Race between Education and Technology. Cambridge MA: Harvard University Press.

Greenwood DT (2016) Institutionalist theories of the wage bargain: beyond demand and supply. Journal of Economic Issues 50(2): 406-414.

Hryshko D, Luengo-Prado M, Sorensen B (2012) The effect of education on equity holdings. The B.E. Journal of Economic Analysis and Policy 12(1): 1935-1682.

Huws U, Spencer NH, Syrdal DS, Holts K (2017) Work in the European Gig Economy: Research results from the UK, Sweden, Germany, Austria, the Netherlands, Switzerland and Italy. 
Brussels and Hertfordshire, UK: FEPS (Foundation for European Progressive Studies), UNI-Europa and University of Hertfordshire.

Imbens G and Angrist J (1994) Identification and estimation of local average treatment effects. Econometrica 62(2): 467-475.

Krueger D and Kumar K (2004) Skill-specific rather than general education: a reason for USEurope growth differences? Journal of Economic Growth 9(2): 167-207.

Lemieux T (2006) Post secondary education and increasing wage inequality. American Economic Review 96(2): 195-199.

Lobel O (2019) Regulating the sharing economy: self-governance, efficiency and values. China Global Law Review, Forthcoming; San Diego Legal Studies Paper: 19-419.

Lochner L (2011) Nonproduction benefits of education: crime, health, and good citizenship. Cambridge MA: NBER Working Paper No. 16722. Available at: https://www.nber.org/papers/w16722.pdf (accessed 4 June 2020).

Martin CJ (2016) The sharing economy: a pathway to sustainability or a nightmarish form of neoliberal capitalism? Ecological Economics 121: 149-159.

Minter K (2017) Negotiating labour standards in the gig economy: Airtasker and Unions New South Wales. The Economic and Labour Relations Review 28(3): 438-454.

Newlands G, Lutz C, Fieseler C (2018) Recommendations for the sharing economy: (re-) balancing power. Available at: SSRN: https://ssrn.com/abstract=3106584 (accessed 14 January 2020). Organisation for Economic Cooperation and Development (OECD) (2017) Digital platforms for facilitating access to research infrastructures. OECD Science, Technology and Industry Policy Papers 49. Paris: OECD Publishing.

Pesole A, Urzí Brancati MC, Fernández-Macías E, Biagi F, González Vázquez I (2018) Platform Workers in Europe. Luxemburg: Publications Office of the European Union.

PwC (2015). The sharing economy. Available at: https://www.pwc.com/us/en/industry/entertainment-media/publications/consumerintelligence-series/assets/pwc-cis-sharing-economy.pdf (accessed 14 January 2020). 
Quattrone G, Proserpio D, Quercia D, Capra L, Musolesi M (2016) Who benefits from the 'Sharing' Economy of Airbnb?. In Proceedings of the 25th International Conference on World Wide Web, Montreal, Canada, April 11 - 15, International World Wide Web Conferences Steering Committee. Available at: https://discovery.ucl.ac.uk/id/eprint/1483036/ (accessed 14 January 2020).

Ravenelle A (2017) Sharing economy workers: selling, not sharing. Cambridge Journal of Regions, Economy and Society 10(2): 281-295.

Schwab, K (2016) The Fourth Industrial Revolution: What it Means, and How to Respond. Cologny, Switzerland: World Economic Forum.

Schor JB (2017) Does the sharing economy increase inequality within the eighty percent? Findings from a qualitative study of platform providers. Cambridge Journal of Regions, Economy and Society 10(2): 263-279.

Schor JB and Attwood-Charles W (2017) The 'sharing' economy: labor, inequality, and social connection on for-profit platforms. Sociology Compass. 11(8): e12493.Available at: https://doi.org/10.1111/soc4.12493 (accessed 4 June 2020).

Schor JB, Fitzmaurice C, Attwood-Charles W, Carfagna LB, Dubois, E (2016) Paradoxes of openness and distinction in the sharing economy. Poetics 54: 66-81.

Smith A (2016) Shared, Collaborative and On Demand: The New Digital Economy. Washington DC: Pew Research Center.

Sobel I (1982) Human capital and institutional theories of the labor market: rivals or complements? Journal of Economic Issues 16(1): 255-272.

Stewart A and Stanford J (2017) Regulating work in the gig economy: what are the options? The Economic and Labour Relations Review 28(3): 420-437.

Stanford J (2017) The resurgence of gig work: historical and theoretical perspectives. The Economic and Labour Relations Review 28(3): 382-401.

Stock J and Yogo M (2005) Testing for weak instruments in Linear IV regression. In: Andrews DWK (ed.) Identification and Inference for Econometric Models. New York NY: Cambridge University Press, pp. 80-108. 
Sundararajan A (2016) The Sharing Economy: The End of Employment and the Rise of CrowdBased Capitalism. Cambridge MA: MIT Press.

Thebault-Spieker J, Tervee LG and Hecht B (2015) Avoiding the South Side and the suburbs: the geography of mobile crowdsourcing markets. ACM Press. In: Proceedings of the 18th ACM Conference on Computer Supported Cooperative Work and Social Computing (CSCW1'5), pp. 265-275. Available at: https://doi.org/10.1145/2675133.2675278 (accessed 1 June 2020).

Thurow LC (1975) Generating Inequality. London UK: MacMillan Press.

Torero M and von Braun J (2006) Information and Communication Technologies for Development and Poverty Reduction: The Potential of Telecommunications. Washington DC: Johns Hopkins University Press e IFPRI.

Van Dijk J (2005) The Deepening Divide Inequality in the Information Society. London UK: Sage Publications.

Van Laar E, van Deursen AJAM, van Dijk JAGM and de Haan J (2017) The relation between 21stcentury skills and digital skills: A systematic literature review. Computers in Human Behavior 72: 577-588.

Verwiebe R, Wiesböck L and Teitzer R (2014) New forms of intra-European migration, labour market dynamics and social inequality in Europe. Migration Letters 11(2): 125-136.

Williamson OE (1981) The economics of organization: the transaction cost approach. American Journal of Sociology 87(3): 548-577.

Wu Y, Damnée S, Kerhervé H, Ware C and Rigaud A (2015) Bridging the digital divide in older adults: a study from an initiative to inform older adults about new technologies. Clinical Interventions in Aging 10: 193-200. 


\section{Author biographies}

Jesús M. Artero is a PhD student at the University of Seville. His research focuses on the assessment of public policies and collaborative economy. He can be contacted at jesartlop@alum.us.es

Cristina Borra is Associate Professor of Microeconomics and Labour Economics at the University of Seville. She is an applied micro economist whose research focuses on Labour and Population Economics, specifically on the areas of gender, child development, and human capital.

Rosario Gómez-Alvarez is Associate Professor of Economics in Department of Economics and Economy History at the University of Seville. She is an expert on economic inequality and public policies and collaborative economy. She can be contacted at charogomez@us.es. 
Figure 1. Accumulated university openings in Euro-28. Years 1934-2015, absolute values.

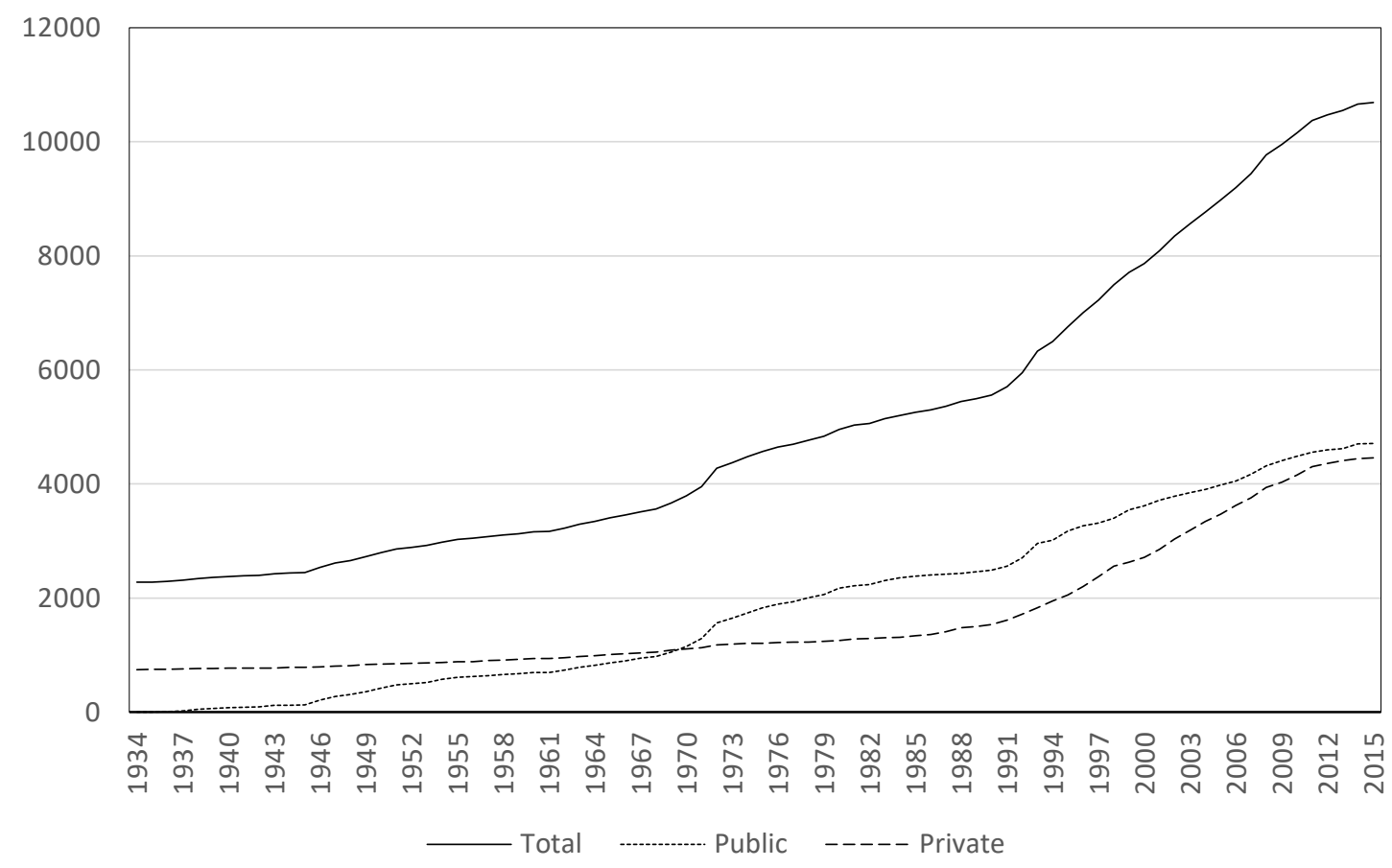

Source: ETER (2018) dataset 
Table 1. Main estimated impact of Years of schooling on use of DCPs.

(1)

(2)

VARIABLES

OLS Specification

IV Specification

Years of schooling

$0.0059 * * *$

$0.0503 * * *$

$(0.001)$

$(0.018)$

Cohort FE

Region FE

Observations

13,007

13,007

First Stage Results

Instrument (\# universities at 16)

Yes

Yes

Yes

Yes

$0.0204 * * *$

$(0.004)$

F-Test

Prob $>$ F

0,000

Mean of dep. var.

$0.178(0.383)$

Each column corresponds to a different regression. The table shows the OLS and IV regression results of an indicator of DCPs use on the education variable. Additional controls are gender and rural community dummies. The sample includes all individuals aged at least 16 years. Sample weights used.

* Significant at $10 \%$;* significant at $5 \%$; *** significant at $1 \%$ 
Table 2. Heterogeneity of results by gender.

\begin{tabular}{|c|c|c|c|c|}
\hline & (1) & (2) & (3) & (4) \\
\hline & \multicolumn{2}{|c|}{ Females } & \multicolumn{2}{|c|}{ Males } \\
\hline VARIABLES & $\begin{array}{l}\text { OLS } \\
\text { Spec. }\end{array}$ & IV Spec. & $\begin{array}{l}\text { OLS } \\
\text { Spec. }\end{array}$ & IV Spec. \\
\hline \multirow[t]{2}{*}{ Years of schooling } & $0.0046 * * *$ & $0.0527 * *$ & $0.0080 * * *$ & $0.0580 * *$ \\
\hline & $(0.001)$ & $(0.024)$ & $(0.001)$ & $(0.029)$ \\
\hline Cohort FE & Yes & Yes & Yes & Yes \\
\hline Region FE & Yes & Yes & Yes & Yes \\
\hline Observations & 7,630 & 7,630 & 5,377 & 5,377 \\
\hline \multicolumn{5}{|l|}{ First Stage Results } \\
\hline \multirow[t]{2}{*}{$\begin{array}{l}\text { Instrument (\# universities at } \\
\text { 16) }\end{array}$} & & $0.0194 * * *$ & & $0.0213 * * *$ \\
\hline & & $(0.006)$ & & $(0.007)$ \\
\hline F-Test & & 11.52 & & 10.32 \\
\hline Prob $>\mathrm{F}$ & & 0,000 & & 0,001 \\
\hline Anderson-Rubin Wald Test & & 6.008 & & 5.605 \\
\hline Prob $>$ A-R Test & & 0.0143 & & 0.0180 \\
\hline Mean of dep. var. & 0,152 & $(0.359)$ & 0,208 & $(0.405)$ \\
\hline \multicolumn{5}{|c|}{$\begin{array}{l}\text { Each column corresponds to a different regression. The table shows the OLS and IV } \\
\text { regression results of an indicator of DCPs use on Years of schooling. Additional controls } \\
\text { are gender and rural community dummies. The sample includes all women (men, in } \\
\text { Columns } 3 \text { and } 4 \text { ) aged at least } 16 \text { years. Sample weights used. } \\
* \text { Significant at } 10 \% ; * * \text { significant at } 5 \% \text {;** significant at } 1 \%\end{array}$} \\
\hline
\end{tabular}




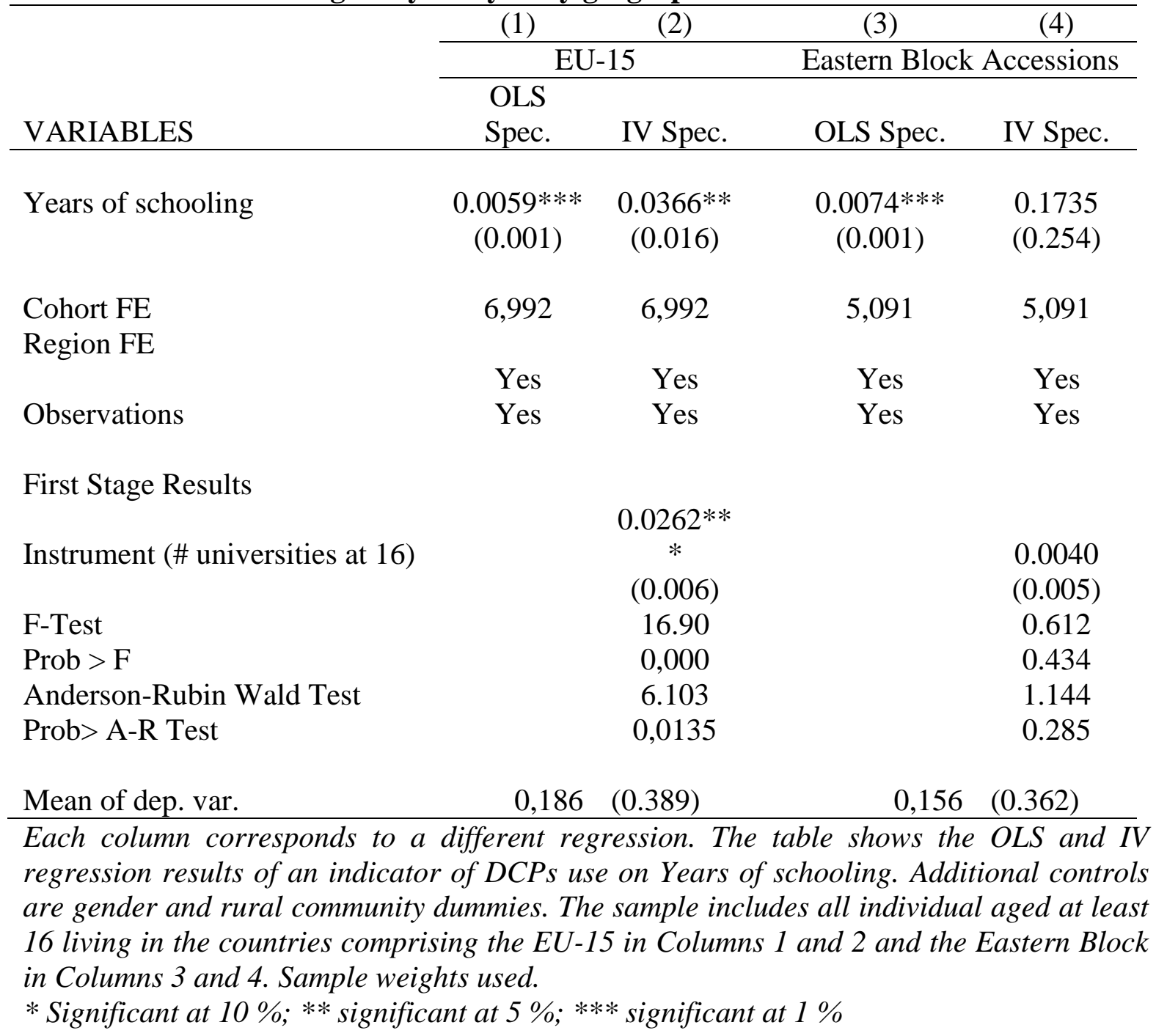


${ }^{1}$ Transaction costs refer to the costs involved in market exchange, including the costs of learning about markets and prices, the costs of bargaining and drawing appropriate contracts and the costs of enforcing the agreements. Transaction costs economics emphasizes that hierarchical institutions such as firms arise to minimize the transaction costs of operating through markets (Coase, 1960; Williamson, 1981; Lobel, 2019).

${ }^{2}$ Human capital theory rests in the assumption that education increases the individual's skills and productivity and ultimately her earnings (Becker, 1962). The skill-biased technological change hypothesis suggests that technological change shifts labour demand towards the highly skilled and consequently highly educated workers benefit from the implementation of new technologies. However, such wage premiums are temporary, and in the long run market forces ensure the balancing of skill supply and skill demand, causing returns to flatten or decline (Acemoglu 2002; DiMaggio and Bonidowski, 2008).

${ }^{3}$ Institutionalist theories of wage bargaining emphasize that productivity resides in the job rather than in the individual hired to perform it. In the job competition model, there is a labour queue of individuals facing a distribution of jobs and earnings. An individual's position in the labour queue is based on perceived training costs, which is inversely related to educational qualifications. Consequently, the best jobs in the labour queue are allocated to individuals with higher qualifications (Thurow, 1975; Sobel, 1982; Greenwood, 2016).

4 Examples of OLMs, digital labour markets that allow remote delivery of electronically transmittable services, include Freelancers, Amazon Mechanical Turk, and Upwork; examples of MLMs, digital labour markets that require direct interaction for the physical delivery of the services, include Uber, Deliveroo, and TaskRabbit.

${ }^{5}$ IV methods can usually only identify the impact of the main regressor on the outcome for the subpopulation induced by the instrument to change the value of the endogenous regressor. In our case, using the number of universities in the region as an instrument for years of education can only identify the impact of an additional year of education for those individuals induced to increase their years of study by an additional university opening in the region. In this respect, this estimated impact is considered a local estimate, that is, a local average treatment effect or LATE (Imbens and Angrist, 1994).

${ }^{6}$ We provide a discussion of the validity of the instrument in the Online Appendix C. 